\title{
EX VIVO IMMUNE RESPONSES IN FRESHWATER FISH LEUCOCYTES EXPOSED TO ENVIRONMENTAL SEROTYPES OF LIPOPOLYSACCHARIDES
}

\author{
Hakim Chouki Samaï ${ }^{1 \S}$, Damien Rioult ${ }^{2}$, Laurence Delahaut ${ }^{1}$, Alain Geffard ${ }^{1}$, Jean-Marc Porcher ${ }^{3}$ \\ and Stéphane Betoulle ${ }^{1,2}$ \\ , ' Université de Reims Champagne-Ardenne, UMR-I 02 SEBIO (Unité Stress Environnementaux et Biosurveillance \\ des milieux aquatiques, UFR des Sciences Exactes et Naturelles, BP 1039, 51687 Reims Cedex 2 \\ ${ }^{2}$ Université de Reims Champagne-Ardenne/INERIS, Plateau technique mobile en cytométrie environnementale \\ MOBICYTE, UFR des Sciences Exactes et Naturelles, BP 1039, 51687 Reims Cedex 2 \\ ${ }^{3}$ Institut National de l'Environnement Industriel et des Risques (INERIS), UMR-I O2 SEBIO (Unité Stress \\ Environnementaux et Biosurveillance des milieux aquatiques, Unité d'Ecotoxicologie in vitro in vivo, BP2, 60550, \\ Verneuil-en-Halatte, France
}

\section{ABSTRACT}

In aquatic ecosystems, detected endotoxins or lipopolysaccharide (LPS) contamination can be linked to cyanobacteria blooms or enterobacterial contaminations. Water contaminations by endotoxins is of particular interest as these microbiological molecules may be released in freshwater often in combination with other chemicals (pharmaceutics...). Their immunomodulatory properties rise interest towards their proinflammatory action on mammalians and aquatic vertebrates. Despite the fact that some E.coli LPS serotypes such as O55:B5 are often used as immunostimulant in experimentations, no data are available concerning some other serotypes as $\mathrm{O} 157: \mathrm{H} 7$ even if they may significantly contaminate freshwater ecosystems, particularly in agricultural field contexts.

We aimed to compare here the immunomodulation patterns potentially induced by two E.coli LPS serotypes (O55:B5 and O157:H7) alone or in combination with diclofenac, an anti-inflammatory drugs which chronically contaminate European freshwaters. Using an ex vivo approach, we studied immune parameters (Oxidative activity, Phagocytosis and cytotoxicity) of roach (Rutilus rutilus) leucocytes populations (lymphocytes, monocytes/macrophages and granulocytes) isolated from blood, head-kidney and spleen in response to endotoxins exposure. Leucocytes were exposed from 6 to 12 hours to sub-lethal concentrations of LPS and/or diclofenac ( $1 \mu \mathrm{g} / \mathrm{mL}$ LPS, $0,1 \mu \mathrm{M}$ diclofenac) determined from preliminary results.

Like diclofenac, endotoxins induced significant decrease in intracellular ROS production by leucocytes at time 0. After 12 hours of exposure to the E.coli O55:B5 LPS / diclofenac combination, the oxidative activity was stimulated in spleen leucocytes and, simultaneously, they showed a significant decrease in phagocytosis. Moreover, while the E.coli O157:H7 LPS alone showed tendencies to decrease phagocytic activity, the two endotoxin / diclofenac combinations significantly decreased it in head-kidney leucocytes after 6 hours.

All these results will be set versus an ongoing in vivo experiment which would allow us to study more inflammation aspects like cytokines and immune-related factors production.

Whereas environmental monitoring and studies of endotoxins presently concern only human health like in wastewater units, our results rise the questioning on environmental reality of endotoxins and their potential immunomodulations in fish.

KEYWORDS: Lipopolysaccharides, Fish, Oxidative stress, Phagocytosis ${ }^{\S}$ Corresponding author. Tel.: +33 627995522. E-mail: hakim-chouki.samai@univ-reims.fr 